\title{
ERRATUM
}

\section{Diffusion coefficient of copper, tin and copper tin alloy}

\author{
M. Mouas, J.-G. Gasser, S. Hellal, B. Grosdidier, A. Makradi and S. Belouettar \\ EPJ Web of Conferences 1501013 (2011) \\ DOI: $10.1051 /$ epjconf/20111501013
}

1) In figure 6-b the calculated interdiffusion coefficient values in $\mathrm{Sn}_{95.6 \%} \mathrm{Cu}_{4.4 \%}$ are presented with a scale: $\mathrm{D}\left(10^{-5} \mathrm{~cm}^{2} / \mathrm{s}\right)$. The correct interdiffusion values should be presented with a scale: $\mathrm{D}\left(10^{-4} \mathrm{~cm}^{2} / \mathrm{s}\right)$. The corrected figure is given below.

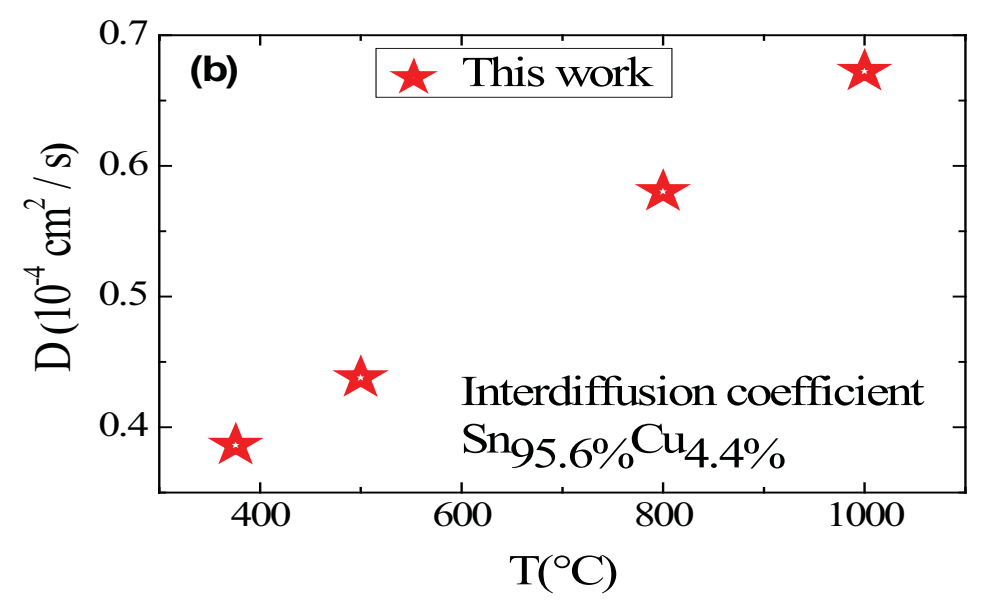

Fig. 6: (b) Interdiffusion in $\mathrm{Sn}_{95.6 \%} \mathrm{Cu}_{4.4 \%}$ (in at. \%) as a function of temperature.

2) In the conclusion, please replace "The interdiffusion coefficient in $\mathrm{Sn}_{95.4 \%} \mathrm{Cu}_{4.4 \%}$ alloy is in good agreement with experimental measurement" by "The total calculated structure factors in the $\mathrm{Sn}_{95.6} \% \mathrm{Cu}_{4.4} \%$ alloy are in good agreement with experimental measurements".

3) In the formula describing $w_{0}(r)$ replace $-\frac{Z_{\text {eff }}}{r} \quad r<R_{C} \quad$ by $\quad-\frac{Z_{\text {eff }}}{r} \quad r>R_{C}$.

4) In numbers in the text and in the scales of all figures, please replace commas (,) by decimal dots (.)

5) At the end of the main text, please replace $\mathrm{Sn}_{95.4 \%} \mathrm{Cu}_{4.4 \%}$ by $\mathrm{Sn}_{95.6 \%} \mathrm{Cu}_{4.4 \%}$. 